\title{
Changes in Peripheral Lymphocyte Subsets in the Type 1 Diabetic Dogs Treated with Insulin Injections
}

\author{
Akihiro MORI ${ }^{1) *}$, Fumi SAGARA ${ }^{1)}$, Sumire SHIMIZU ${ }^{1)}$, Hisashi MIZUTANI ${ }^{1)}$, Toshinori SAKO ${ }^{2)}$, Hisashi HIROSE ${ }^{1)}$, \\ Itaru YOSHIMURA ${ }^{3)}$, Yosuke UEMATSU ${ }^{4)}$, Tomohiro YAMAGUCHI ${ }^{4)}$ and Toshiro ARAI ${ }^{1)}$ \\ ${ }^{1)}$ Departments of Veterinary Science and ${ }^{2)}$ Veterinary Nursing, School of Veterinary Medicine and ${ }^{3)}$ Department of Animal Science, \\ Faculty of Applied Life Science, Nippon Veterinary and Life Science University and ${ }^{4}$ Canine Laboratory Ltd., 1-7-1 Kyonancho, \\ Musashino, Tokyo 180-8602, Japan
}

(Received 25 July 2007/Accepted 26 September 2007)

ABSTRACT. Plasma metabolites and peripheral lymphocyte subsets were measured in ten diabetic and ten control dogs to investigate their significances as indicators to evaluate immune states in the diabetic dogs. Diabetic dogs were treated with insulin injections, however their plasma glucose and fructosamine concentrations were significantly higher than those of the controls. There were no significant differences in counts of total white blood cells (WBC) and lymphocyte $\mathrm{CD} 8^{+}$cells (cytotoxic $\mathrm{T}$ cells) between the control and the diabetic dogs. In the diabetic dogs, the counts of $\mathrm{CD}^{+}$( $\mathrm{T}$ cells), $\mathrm{CD}^{+}$(Helper T cells) and $\mathrm{CD} 21^{+}$(B cells) cells and the peripheral lymphocytes CD4/CD8 ratio were significantly lower than those in the control dogs. We confirmed abnormality of lymphocyte subsets in insulin treated diabetic dogs and it may relate to depression of immunocompetence and high susceptibility to common infectious diseases. KEY WORDS: canine, diabetes, lymphocytes.

The major type of diabetes mellitus (DM) observed in dogs is type 1 (insulin dependent) DM, therefore insulin injection is effective treatment for the diabetic dogs [6]. The cause of type $1 \mathrm{DM}$ has been poorly characterized in dogs but is undoubtedly multifunctional and immune mediated $\mathrm{DM}$ is considered to be one of the reasons [1]. In the diabetic dogs, infectious diseases such as conjunctivitis and cystitis are frequently observed accompanying depression of immunocompetence [9]. Lymphocyte subsets have been measured in past various reports to investigate immune states in dogs $[2,3,7]$. Several studies have shown that distribution of peripheral $\mathrm{T}$ lymphocyte subsets are impaired in diabetic humans, both at diagnosis and during the course of the disease $[13,15]$. The aim of the present study was to investigate changes in peripheral blood lymphocyte subsets in the diabetic dogs using canine-specific antibodies.

In the present study, 4 beagles ( 3 male and 1 female, 5- 6 years old), 2 yorkshire terrier (1 male and 1 female, 11 and 12 years old), 2 mix breed (female, 9 and 16 years old), 1 bichon frise (female, 10 years old) and 1 labrador retriever (male, 12 years old) were diagnosed as type 1 (insulin dependent) DM and glycemic-controlled by insulin injections at the animal clinical center of our university, and 10 beagles ( 2 male and 8 female, $6-8$ years old) as healthy control maintained in our laboratory for research were used. Diabetic dogs were defined as DM by clinical signs (polyuria and polydipsia) and documentation of persistent fasting hyperglycemia (over $250 \mathrm{mg} / \mathrm{d} l$ ) and glucosuria. All dogs have no presence of concurrent infectious diseases and all

\footnotetext{
* Correspondence to: Mori, A., Laboratory of Veterinary Biochemistry, Department of Veterinary Science, School of Veterinary Medicine, Nippon Veterinary and Life Science University, 1-7-1 Kyonancho, Musashino, Tokyo 180-8602, Japan. e-mail: D0608@nvlu.ac.jp
}

diabetic dogs have developed diabetes over one year. The diabetic dogs were treated with 0.2 to $1.1 \mathrm{IU} / \mathrm{kg}$ of insulin injections, NPH insulin (Novo Nordisk, Tokyo, Japan) or insulin glargine (Aventis, Tokyo, Japan) twice at 8:00 and 20:00 every day depending on their diabetic states. Blood samples were withdrawn from the jugular vein into tubes containing adequate amounts of EDTA as anticoagulant with animals at rest and unfasted, between 14:00 and 16:00. The plasma was recovered from a part of whole blood by centrifugation at $4^{\circ} \mathrm{C}$ and stored at $-80^{\circ} \mathrm{C}$ until use.

Plasma glucose concentrations were measured by the glucose oxidase method [10]. Plasma fructosamine concentrations were measured by FOD•TOSS method (Auto Wako Fructosamine, Wako Pure Chemical Industries, Tokyo, Japan) using auto-analyzer (Toshiba Medical Systems Corporation, Tokyo, Japan). Plasma immunoreactive insulin (IRI) concentrations were measured by the ELISA method described previously [18].

White blood cell counts were measured using an animal blood counter (Nihon Koden, Tokyo, Japan) according to the manufacture's protocol. Flow cytometry (FACS calibur; Becton Dickinson, Tokyo, Japan) was used to calculate relative percentages of $\mathrm{CD}^{+}$( $\mathrm{T}$ cells), $\mathrm{CD}^{+}$(helper $\mathrm{T}$ cells), $\mathrm{CD}^{+}$(cytotoxic T cells), and $\mathrm{CD} 21^{+}$(B cells) cells using canine-specific antibodies presented in Table 1. Twohundred microlitter of whole blood was mixed with $2 \mathrm{~m} l$ of a commercially available haemolytic solution (FACS Lysis; Becton Dickinson) and incubated for $15 \mathrm{~min}$ at room temperature to lyse red blood cells followed by centrifugation at $200 \mathrm{~g}$ for $5 \mathrm{~min}$ at room temperature to wash peripheral WBC. Appropriate amounts of antibody were added to wash WBC fractions and incubated for $15 \mathrm{~min}$ at room temperature in the dark. Antibodies batches were previously titrated to determine optimum working concentrations. 
Table 1. Monoclonal antibodies used in the present study

\begin{tabular}{llllll}
\hline Phenotype & Specificity & Host & Isotype & Conjugate & Clone \\
\hline CD21 & B-cells & Mouse & IgG1 & RPE $^{\text {a) }}$ & CA2.1D6 \\
CD3 & T-cells & Mouse & IgG1 & FITC $^{\text {b) }}$ & CA17.2A12 \\
CD4 & Helper T-cells & Rat & IgG2a & FITC & YKIX302.9 \\
CD8 & Cytotoxic T-cellsRat & IgG1 & RPE & YCATE55.9 \\
\hline
\end{tabular}

a) RPE, Rhodophyceae phycoerythrin; b) FITC, Fluorescein isothiocyanate isomer I.

Excess primary antibody was then removed by the addition of $2 \mathrm{~m} l$ of PBS and washed. Finally, cells were resuspended in $500 \mu l$ of commercially available solution (FACS FLOW; Becton Dickinson) and stored at $4^{\circ} \mathrm{C}$ until analysis. Samples were analysed using FACSCaliburTM flow cytometer and Cell QuestTM software (Becton Dickinson). Phenotype were analyzed on the peripheral lymphocytes obtained by gating on the screen of forward scatter versus side scatter dot plot of FACS Calibur. For each sample, data for 5,000 events in the lymphocyte gates were saved. Percentages of $\mathrm{CD}^{+}, \mathrm{CD}^{+}, \mathrm{CD}^{+}$and $\mathrm{CD} 21^{+}$were categorized by differences of surface marker in lymphocytes of 5,000 events. Absolute values for lymphocyte subsets were calculated using counts obtained from WBC analysis in combinations with the flow cytometer.

The values are presented as means \pm SD. Difference in plasma metabolites, white blood cell counts and lymphocyte subsets between control and diabetic dog were analyzed by Student's $t$-test (Sigma Stat 3.0 for Windows, Hulinks, Tokyo, Japan) to compare the mean values. A differences of $\mathrm{P}<0.05$ was considered statistically significant.

In the diabetic dogs, plasma glucose and fructosamine concentrations were significantly higher than the control dogs values notwithstanding their higher plasma IRI concentrations owing to insulin injections (Table 2). There was no significant difference in total counts of peripheral WBC between control and diabetic dogs. Total counts of lymphocytes, $\mathrm{CD}^{+}, \mathrm{CD}^{+}, \mathrm{CD} 21^{+}$cells in the diabetic dogs significantly lower than those in the control dogs. There was no significant difference in total counts of $\mathrm{CD}^{+}$between control and diabetic dogs. CD4/CD8 ratios in the diabetic dogs were significantly lower than that in the control dogs (Table 2).

The mean plasma glucose concentrations in the diabetic dogs in the present study were maintained around $141 \mathrm{mg} / \mathrm{d} l$ with insulin injections, and the plasma fructosamine concentrations were significantly higher than those in the controls. Fructosamine are glycated proteins found in blood that are used to monitor control of hyperglycemia in diabetic dogs and its reference ranges were higher than values of our control dogs [14]. This cause is difference of measurement methods and our laboratory's reference range of fructosamine is $101 \pm 21 \mu \mathrm{mol} / \mathrm{L}$ [19]. Clinical conditions of these diabetic dogs were good with insulin injection, and polydipsia and polyuria were resolved. Consequently glycemic control by insulin injections was considered to be slightly impaired in the diabetic dogs in the present study.
Table 2. Plasma glucose, fructosamine and IRI concentrations and peripheral blood cells counts in control and diabetic dogs

\begin{tabular}{lcc}
\hline & Control $(\mathrm{n}=10)$ & Diabetic $(\mathrm{n}=10)$ \\
\hline Glucose $(\mathrm{mg} / \mathrm{d} l)$ & $90 \pm 5$ & $141 \pm 72^{\mathrm{a})}$ \\
Immunoreactive insulin $(\mu \mathrm{U} / \mathrm{m} l)$ & $25 \pm 8$ & $32 \pm 19$ \\
Fructosamine $(\mu \mathrm{mol} / \mathrm{L})$ & $107 \pm 9$ & $184 \pm 38^{\mathrm{a})}$ \\
WBC $\left(\times 10^{9}\right.$ cells $\left./ \mathrm{L}\right)$ & $9.55 \pm 1.70$ & $10.67 \pm 3.21$ \\
Lymphocytes $\left(\times 10^{9}\right.$ cells $\left./ \mathrm{L}\right)$ & $1.74 \pm 0.30$ & $\left.0.96 \pm 0.42^{\mathrm{b}}\right)$ \\
$\mathrm{CD}$ positive cells $\left(\times 10^{9}\right.$ cells $\left./ \mathrm{L}\right)$ & $1.43 \pm 0.30$ & $\left.0.8 \pm 0.38^{\mathrm{b}}\right)$ \\
$\mathrm{CD} 4$ positive cells $\left(\times 10^{9}\right.$ cells $\left./ \mathrm{L}\right)$ & $0.78 \pm 0.19$ & $\left.0.31 \pm 0.10^{\mathrm{b}}\right)$ \\
$\mathrm{CD} 8$ positive cells $\left(\times 10^{9}\right.$ cells $\left./ \mathrm{L}\right)$ & $0.37 \pm 0.14$ & $0.36 \pm 0.26$ \\
$\mathrm{CD} 4 / \mathrm{CD} 8$ & $2.3 \pm 0.9$ & $\left.1.1 \pm 0.4^{\mathrm{b}}\right)$ \\
$\mathrm{CD} 21$ positive cells $\left(\times 10^{9}\right.$ cells $\left./ \mathrm{L}\right)$ & $0.33 \pm 0.14$ & $\left.0.13 \pm 0.07^{\mathrm{b}}\right)$
\end{tabular}

Values are presented as mean $\pm \mathrm{SD}$.

The numbers in parentheses indicate the number of animals examined. a)Significantly higher $(\mathrm{p}<0.05)$ than the control value.

b)Significantly lower $(p<0.05)$ than the control value.

As diabetic dogs show higher incidence of infectious diseases [9], immune system is considered to be impaired in the diabetic animals. Analysis of peripheral blood lymphocyte subsets were considered to reflect immune states in dogs [2, $3,7]$. We considered that the diabetic dogs may have abnormalities of lymphocyte subsets. Diabetic humans show lower CD4/CD8 ratio differing from the healthy controls and it agrees with our results $[5,12]$. Our data indicate a change in immunological balance, with a reduction in helper T-cell and CD4/CD8 ratio, which may play an important role as effectors in DM [4]. However, the reasons for this unbalance are still un-known. Abnormalities of lymphocyte subsets in diabetic dogs may be induced by insufficient insulin action. Diabetic dogs used in this study have higher plasma glucose and fructosamine concentrations compared to control dogs in spite of their higher insulin concentrations. These findings may suggest that diabetic dogs have insufficient insulin action accompanying insulin resistance. Insulin is believed to maintain the allo-activated state of lymphocytes and to enhance T-lymphocyte responsiveness and support or possibly promote the actions of immunoderived regulatory growth and differential factors $[8,11$, 16]. Since insulin enhances energy requirements and protein synthesis necessary for appropriate T-cell functions, defects in insulin action may lead to inappropriate immunoresponses in various metabolic states such as diabetes [17]. Insufficient insulin action may change in peripheral lymphocyte subsets and induce suppression of immune system in the diabetic dogs. 
Lymphocyte subsets were changed gradually along with age in dogs [2]. We found no significant differences in lymphocytes subsets between over and under 10 years of age in the diabetic dogs in the present study. Abnormalities of lymphocyte subsets induced by DM were considered to be so great as to make little of the influence of aging in dogs.

In the present study, we confirmed abnormality of lymphocyte subsets in insulin treated diabetic dogs and it may relate to depression of immunocompetence and high susceptibility to common infectious diseases. The findings in the present study suggested that as even insulin treated diabetic dogs may be with impaired immune function, prevention of infectious diseases is also important for treatment of diabetic animals.

ACKNOWLEDGMENT. This work was supported in part by 'Academic Frontier' Project for Private University from Ministry of Education, Culture, Sports, Science and Technology of Japan (MEXT), 2005-2009.

\section{REFERENCES}

1. Alejandro, R., Feldman, E.C., Shienvold, F.L. and Mintz, D.H. 1988. J. Am. Vet. Med. Assoc. 193: 1050-1055.

2. Blount, D.G., Pritchard, D.I. and Heaton, P.R. 2005. Vet. Immunol. Immunopathol. 108: 399-407.

3. Chew, B.P., Park, J.S., Wong, T.S., Kim, H.W., Weng, B.B., Byrne, K.M., Hayek, M.G. and Reinhart, G.A. 2000. J. Nutr. 130: 1910-1913.

4. Delovitch, T.L. and Singh, B. 1997. Immunity 7: 727-738.

5. Faustman, D., Eisenbarth, G., Daley, J. and Breitmeyer, J.
1989. Diabetes 38: $1462-1468$.

6. Feldman, E.C. and Nelson, R.W. 2004. pp. 486-538. In: Canine and Feline Endocrinology and Reproduction, 3rd ed., W.B. Saunders, Philadelphia.

7. Greeley, E.H., Spitznagel, E., Lawler, D.F., Kealy, R.D. and Segre, M. 2006. Vet. Immunol. Immunopathol. 111: 287-299.

8. Helderman, J.H. and Strom, T.B. 1977. J. Clin. Invest. 59: 338-344.

9. Hess, R.S., Saunders, H.M., Van Winkle, T.J. and Ward, C.R. 2000. J. Am. Vet. Med. Assoc. 217: 1166-1173.

10. Huggett, A.G. and Nixon, D.A. 1957. Lancet 273: 368-370.

11. Kumagai, J., Akiyama, H., Iwashita, S., Iida, H. and Yahara, I. 1981. J. Immunol. 126: 1249-1254.

12. Lapolla, A., Dalfra, M.G., Sanzari, M., Fedele, D., Betterle, C., Masin, M., Zanchetta, R., Faggian, D., Masotti, M., Nucera, V. and Plebani, M. 2005. Cytokine 31: 280-287.

13. Petersen, L.D., Duinkerken, G., Bruining, G.J., van Lier, R.A., de Vries, R.R. and Roep, B.O. 1996. J. Autoimmun. 9: 731737.

14. Reusch, C.E., Liehs, M.R., Hoyer, M. and Vochezer, R. 1993. J. Vet. Intern. Med. 7: 177-182.

15. Roep, B.O. 2003. Diabetologia 46: 305-321.

16. Snow, E.C., Feldbush, T.L. and Oaks, J.A. 1980. J. Immunol. 126: $161-164$.

17. Stentz, F.B. and Kitabchi, A.E. 2003. Curr. Drug. Targets. 4: 493-503.

18. Tanaka, A., Urabe, S., Takeguchi, A., Mizutani, H., Sako, T., Imai, S., Yoshimura, I., Kimura, N. and Arai, T. 2006. Vet. Res. Commun. 30: 29-38.

19. Watanabe, D., Nakara, H., Akagi, K., Ishii, T., Mizuguchi, H., Nagashima, Y. and Okaniwa, A. 2004. J. Toxicol. Sci. 29: 3336. 